UDC 539.125.5

\title{
STUDY OF WATER INFILTRATION INTO CEMENT-BASED MORTARS USING REAL-TIME THERMAL NEUTRON RADIOGRAPHY
}

\author{
Nazarov K.M. ${ }^{1,2 *}$, Kichanov S.E. ${ }^{1}$, El Abd A. ${ }^{3}$, Taman M. ${ }^{4}$, Kozlenko D.P. ${ }^{1}$ \\ ${ }^{1}$ Frank Laboratory of Neutron Physics, Joint Joint Institute for Nuclear Research, Dubna, Russia, \\ knazarov@jinr.ru \\ 2Faculty of Physics and Technology, L.N. Gumilyov Eurasian National University, Nur-Sultan, Kazakhstan \\ ${ }^{3}$ Reactor Physics Department, Nuclear Research Center, Atomic Energy Authority, Cairo, Egypt \\ ${ }^{4}$ Department of Structural Engineering, Faculty of Engineering, Tanta University, Tanta, Egypt
}

\begin{abstract}
Water absorption into cement mortar with different water to cement ratio was studied using neutron radiography in order to assess the durability and stability of these mortars. While the samples absorb water, neutron radiography images were acquired regularly as the absorption time elapses. The time evolution of water front position or penetration depth and the water content distribution along the flow direction were determined based on the specific differences in the interactions of neutrons with various components of the cement mortars and absorbed water. The obtained results were discussed in terms of the capillary theory to obtain the characteristic parameters of water propagation in the cement mortars. It's shown that neutron radiography is a powerful method to study a moisture transport in porous media.
\end{abstract}

Keywords: cement mortars, neutron radiography, moisture transport, water absorption.

\section{Introduction}

Cement mortars are key elements in the construction of building materials, being widely used in different formulas. The operation time of cement-based mortars and concretes strongly depends on the presence of water inside these materials [1,2]. Water transport in porous media such as cement mortar is a crucial process for their durability and stability [3, 4]. Because of water transport inside mortars and concretes materials, the chemical aggressive compounds can be penetrated into them, and accelerate the damage process of these materials [5]. In particular, steel corrosion in reinforced concrete under the moisture content can lead to the local critical destruction of massive concrete construction $[5,6]$. Therefore, the desire to understand the mechanisms of water absorption into cement mortars lead to control of this process by using destructive and non-destructive experimental methods for improving their service life and durability [7-10]. These studies and obtained results are of high value being a base for optimizing the cement materials formulas if required. One of the non-destructive methods is neutron radiography [10,11]. This method is a powerful tool for non-destructive analysis, which has many applications in the studies of water absorption and penetration in porous building materials including mortar, concrete, stones, and bricks [12 -15]. Neutron radiography provides additional benefits to study moisture transport and its spatial distribution inside cement material due to the strong neutron attenuation by the hydrogencontained matter like water.

In the present paper, the results of neutron radiography experiments performed on three types of cement mortars with different water to cement $(\mathrm{w} / \mathrm{c})$ ratios are highlighting the time evolution of waterfront inside the studied cement-based materials.

\section{Sample preparation}

Cement; Ordinary Portland cement (CEM I 42.5N) was used in the present experimental work. The cement specific gravity and specific surface area were 3.13 and $3394 \mathrm{~cm}^{2} / \mathrm{gm}$, respectively. The 
chemical compositions of cement matrix are listed in Table 1. The initial and the final setting times were performed according to [16] and the recorded times were $85 \mathrm{~min}$ and $240 \mathrm{~min}$, respectively.

Sand; standard sand [17] was used for all mortar samples. Table 2 lists the grading of the standard sand used. The silica and moisture content of the used sand were not less than $98 \%$ and less than $0.2 \%$, respectively.

Water; Tap water with $\mathrm{pH}$ value about 7.2 and complied with the limits of [17] was used.

Table 1. The chemical composition of the cement used for the preparation of cement mortar.

\begin{tabular}{|c|c|}
\hline Component & Content, \% \\
\hline $\mathrm{SiO}_{2}$ & 19.6771 \\
\hline $\mathrm{CaO}$ & 61.138 \\
\hline $\mathrm{MgO}$ & 2.4444 \\
\hline $\mathrm{Fe}_{2} \mathrm{O}_{3}$ & 5.6329 \\
\hline $\mathrm{Al}_{2} \mathrm{O}_{3}$ & 3.879 \\
\hline $\mathrm{Na}_{2} \mathrm{O}$ & 0.4269 \\
\hline $\mathrm{K}_{2} \mathrm{O}$ & 0.1672 \\
\hline $\mathrm{Cl}$ & 0.0331 \\
\hline $\mathrm{SO}_{3}$ & 3.0873 \\
\hline Loss of ignition & 3.5003 \\
\hline Total & 99.9865 \\
\hline
\end{tabular}

Table 2. The grading of the standard sand.

\begin{tabular}{|c|c|}
\hline Sieve size, $\mathrm{mm}$ & $\begin{array}{c}\text { \% retained, } \\
\text { cumulative }\end{array}$ \\
\hline 2 & 0 \\
\hline 1.6 & $7 \pm 5$ \\
\hline 1 & $33 \pm 5$ \\
\hline 0.5 & $67 \pm 5$ \\
\hline 0.16 & $87 \pm 5$ \\
\hline 0.08 & $99 \pm 1$ \\
\hline
\end{tabular}

Three mortar mixtures were mixed with different water/cement $(\mathrm{W} / \mathrm{C})$ ratios of $0.42,0.45$ and 0.65 . The binder to sand ratio was kept constant of $1 / 3$ as listed in Table 3 . Each mix was mixed mechanically according to [17]. After mixing, the mortar was cast in moulds of 40x40x160 mm in dimension and kept in moist cabin for 24 hours. For each mix, 6 prisms of the dimension of 40x40x160 mm were cast. After that the specimens were demolded and kept in water of temperature of $25 \pm 2 \mathrm{C}^{\circ}$ till the test.

For each fresh mortar mix, the flow test was performed according to [18]. The recorded flow percentage was measured after the standard number of shaking cycles of 25. Table 3 lists the flow ratio for the three mixes. It can be noticed that, the $\mathrm{W} / \mathrm{C}$ ratio has a positively effect on the flow percentage of the fresh mortar where, the W/C ratio of 0.65 increased the flow to about $735 \%$ compared to that of $0.42 \mathrm{~W} / \mathrm{C}$ ratio.

Table 3. The results of the tests for flow and compressive strength of samples.

\begin{tabular}{|c|c|c|c|c|c|c|}
\hline Sample & Cement & Sand & Water & Flow (\%) & \multicolumn{2}{|c|}{ Compressive strength (MPa) } \\
\cline { 5 - 7 } & & & & & Age of 2 days & Age of 28 days \\
\hline$\# 1$ & 1 & 3 & 0.42 & 21.4 & 26.4 & 48.0 \\
$\# 2$ & 1 & 3 & 0.45 & 73.8 & 22.6 & 52.8 \\
$\# 3$ & 1 & 3 & 0.65 & 178.6 & 14.4 & 35.0 \\
\hline
\end{tabular}

The compressive and flexural strength tests of the mortar samples were carried out at 2 and 28days ages according to [17]. The results of the compressive strength were recorded in Table 3 . It can be noticed that, the lower the water/ cement ratio, the higher the compressive strength for the two ages of tests. 


\section{Experimental methods}

Three mortar samples were chosen for the neutron radiography experiments. We introduce the notation of the studied samples as Sample\#1, Sample\#2 and Sample\#3, which corresponds to water/cement $(\mathrm{w} / \mathrm{c})$ ratios of $0.42,0.45$, and 0.65 , respectively. The dry cement mortars were covered with a special type of acrylic paint from all sides except their ends to prevent evaporation and to allow water to flow in one dimension during the absorption process.

The experiments of neutron radiography were performed at the neutron radiography and tomography facility $[19,20]$ and placed on beamline 14 of the IBR-2 high-flux pulsed reactor. Neutron radiography images have been collected by a CCD-based detector system with a maximum field of view of $20 \times 20 \mathrm{~cm}$. The imaging data were corrected by subtracting the camera dark current image and normalizing to the image of the incident neutron beam using the Image $J$ software [21].

The studied samples were placed in a container with water. The neutron radiography images were collected with duration of 30 seconds per frame and a delay between frames of 47 sec. Exposure starts 247 seconds after specimens have been placed in water. For 4.5 hours, the 202 radiography images were collected. Each image corresponds to the time of a duration of the capillary water transport inside the studied cement mortars. The small cadmium foils were fixed on the studied cement samples for an additional correction for scattered neutrons.

The basic calculation for the time evolution of the water front positions in the cement mortars was performed based on previous works $[11,12,22]$.

\section{Results and discussions}

The result of signal generation based on the proposed analytical model (Equation (4)) in the time and frequency domains are shown in Fig. $2 \mathrm{a}$ and $2 \mathrm{~b}$. The direct signal propagates over the shortest distance and has greater energy characteristics than the reflected ones.

Examples of the neutron radiographic images of the cement mortars obtained at different times of the capillary water absorption are shown in Figure 1. Because the neutron attenuation coefficient of water is greater due to the large incoherent neutron scattering cross section, waterfront contrasts well with the cement materials in the neutron radiography images (Figure 1).

It can be seen that the water fronts are irregular and have complex shapes which can be attributed to the inhomogeneous structure of the samples resulting from manufacturing process and may be related to surface cracks, which decrease with increasing distance from the surface $[11,12]$. As the absorption time elapses, the waterfronts proceed into the samples however, with different rates.

The water content distributions along the flow direction $x$ as a function of the absorption time were extracted from the acquired neutron images (simply water profiles, $\theta(x, t)$ ) according to

$$
\theta(x, t) \approx \ln \left(\frac{I_{\text {dry }}}{I_{\text {dry }+ \text { wetted }}}\right)
$$

where $I_{d r y}$ and $I_{d r y+\text { wetted }}$ are total transmitted neutron fluxes (intensities or brightness) for the dry and wetted sample, respectively.

The procedures used to correct for neutron scattering using Cd strip will be discussed in a forthcoming paper. A rectangular area was drawn along the flow direction for every image obtained (Fig. 1). The neutron intensities extracted from the dry and wetted sample images altogether with Eq. 1 were used to determine the water profiles. The profiles determined for Sample \#1, Sample \#2 and Sample \#3 are shown Figs. 2a, $2 \mathrm{~b}$ and 2c, respectively.

The results shown in Fig. 2 show that as the absorption time increases, water profiles migrate into deeper distances in the samples. The process of water absorption into sample $\# 1(\mathrm{w} / \mathrm{c}=0.42)$ is the slowest in comparison with the other samples and it is hardly to recognize any signs of water. At the largest absorption time (Fig. 2a), sample \#1 started to absorb too small amounts of water. 


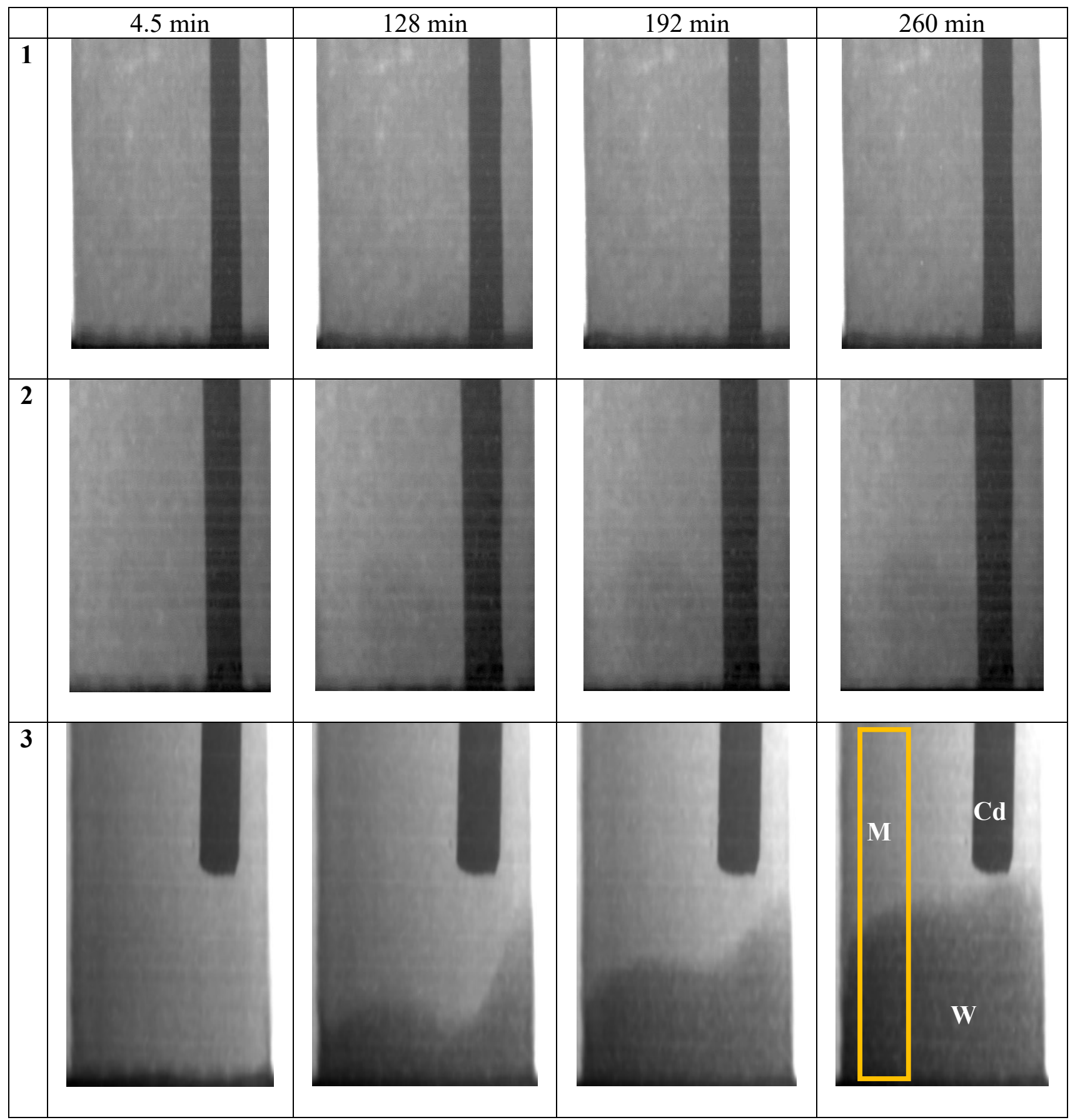

Fig.1. The neutron radiography images of the cement mortars of Sample \#1, Sample\# 2 and Sample\#3 for the different exposure times.

On Fig. 1 the gray regions correspond to neutron attenuation in the cement materials. The darker areas are high neutron attenuate regions of penetrating water. The black stripe is cadmium foil shadow. The "M", "W" and "Cd" mark the mortar, water and cadmium materials, respectively. The yellow bar marks the region used to calculate the water profiles.

It is noticed from the shape of the water profiles for sample $\# 2(\mathrm{w} / \mathrm{c}=0.45)$ and sample\#3 $(\mathrm{w} / \mathrm{c}=0.65)$ that the water contents are slightly decrease with distance along the flow direction till the water front regions. Additionally, sharp fronts characterize these samples. As the w/c increases, the porosity increases and hence the water absorption increases [22, 23]. Thus, water absorption by sample \#3 is higher than that of sample \#2. Namely, the amount of water absorbed by sample \#3 is higher than that of sample \#2. 


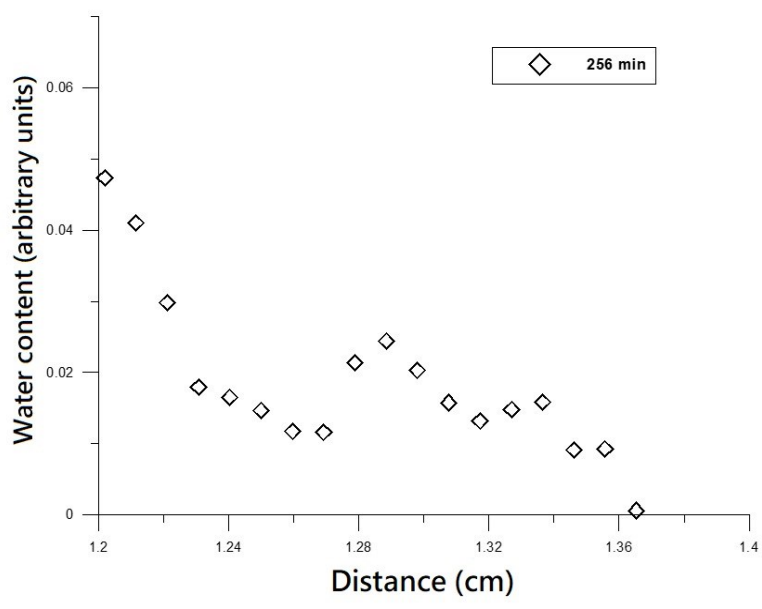

a

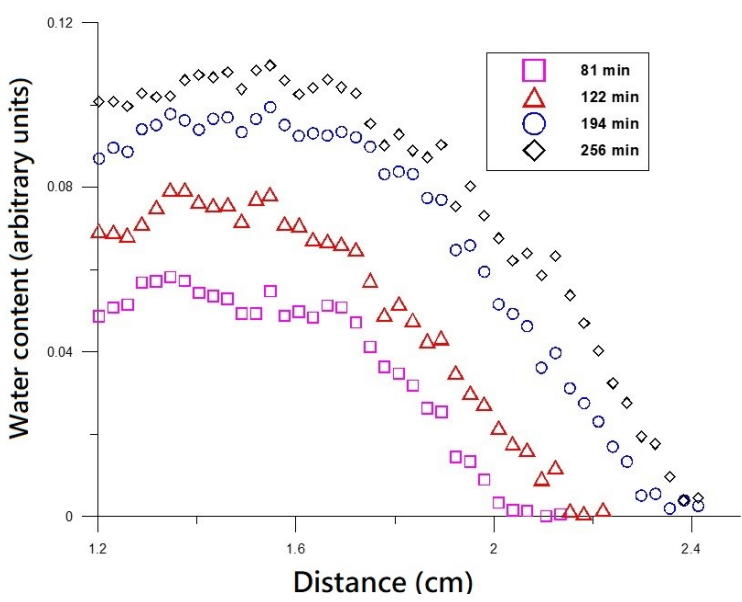

$\mathrm{b}$

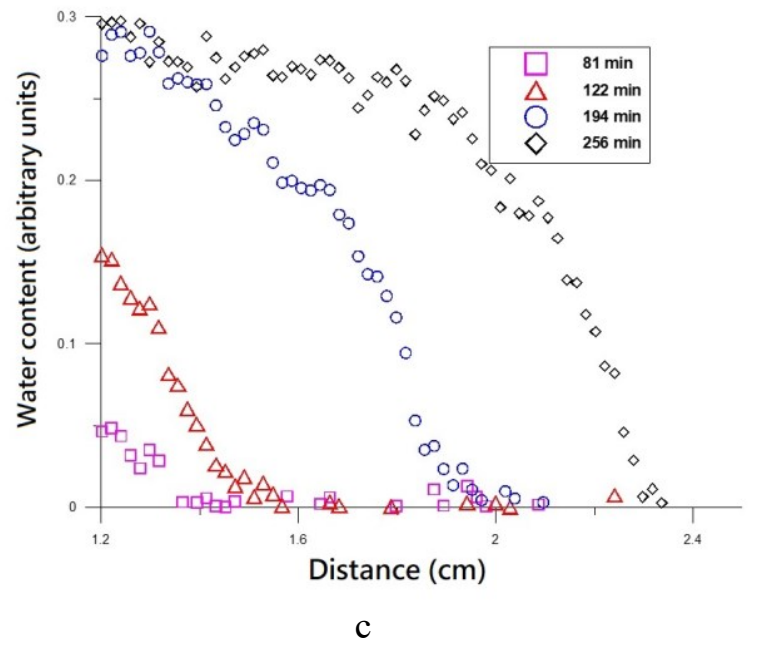

Fig.2. Water front profile for Sample: a) $\# 1, w / c=0.42 ; b) \# 2, w / c=0.45 ; c) \# 3$, w/c $=0.65$

Water front positions (penetration depth) were determined from the water profiles of the investigated samples. The water penetration into cement mortar samples can be estimated in terms of the capillary theory $[12,22,24,25]$. According to this theory the penetration depth (water front position) as a function of time can be described by means of the following simple equation $[10,11]$ :

$$
x(t)=B * \sqrt{t},
$$

where $x(\mathrm{t})$ stands for the penetration depth at time $\mathrm{t}$ and $\mathrm{B}$ is the coefficient of water penetration.

The coefficient of water penetration $B$ was first termed the sorptivity [26]. It lambs the physical parameters of both the flowing liquid and the porous medium such as viscosity, surface tension contact angle and the radii of the porous medium [27]. The water penetration depths were determined from the water profiles. The penetration depth as a function of square root of time in hours is shown in Figure 3. As can be seen, the water front positions for mortar samples with $\sqrt{t}$ are varied, however, with a different behavior. It is observed that the water penetrated distances for sample \#2 are higher than that of sample\#3 - it seems that there is a sudden jump of water inside sample \#2, once water touches its immersed end.

During the initial period of water absorption, water fronts proceed quickly in sample \#2 than in the advanced period. This is indicated by the slopes of the straight fit lines. However, the situation for sample \#3 is different; water absorption during the initial period is slower than the advanced one. The calculated coefficients of water penetration $B$ for the Sample $\# 2$ are $6.18 \mathrm{~mm} / \mathrm{h}^{1 / 2}$ and 4.48 
$\mathrm{mm} / \mathrm{h}^{1 / 2}$ for the initial and advanced periods of water absorption, respectively. The corresponding values for sample $\# 3$ are $7.23 \mathrm{~mm} / \mathrm{h}^{1 / 2}$ and $15 \mathrm{~mm} / \mathrm{h}^{1 / 2}$.

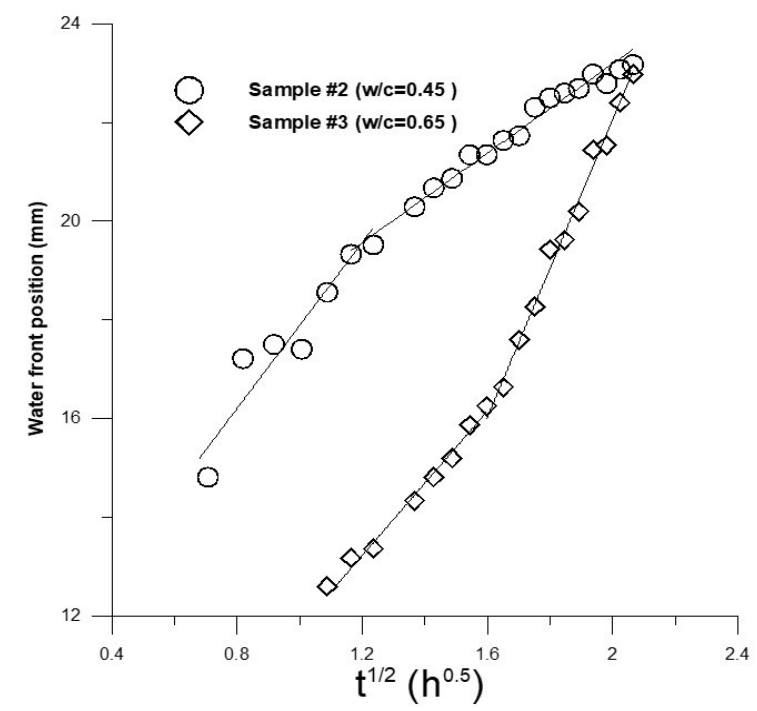

Fig.3. The water front positions versus square root of absorption time for sample $\# 2$ and $\# 3$ along with straight line fits

The initial and advanced periods of water absorption characterizing the mortar samples investigated in this work were previously observed for some mortar samples in [28]. Additionally, the calculated values of water penetration $B$ lie in the ranges reported in $[11,28]$. As the $\mathrm{W} / \mathrm{C}$ ratio increases, both the flow percentage of the fresh mortar and water absorption (water penetration $B$ ) increase, however the corresponding compressive strength decreases.

\section{Conclusion}

The real-time neutron radiography method and the analytical procedures used have proven to be effective for studying the processes of moisture transfer in cement mortars. In our research, we observed that different ratios of water/cement lead to dramatic changes in the mechanisms of moisture absorption inside the cement mortar samples.

Firstly, it should be correlated with the features of the structure of cement mortars, where an interface between aggregates and grains of the cement paste can form some dominant ways for the water penetration. The different interactions between those mortars components lead to damages, cracks or inner voids in the cement materials. Secondly, the faster water penetration in the first hours of the experiment corresponds to cracks in the side edges of studied cement mortars because of the mechanical treatments. These external cracks can be paths of the dominant infiltration of water into the thickness of the cement mortar, where the described above type of the pores and capillaries dominants.

\section{REFERENCES}

1 Phillipson M.C., Baker P.H., Davies M., et al. Moisture measurement in building materials: an overview of current methods and new approaches. Build. Serv. Eng.Res.T. 2007, Vol. 28, No. 4, pp. 303316.

2 Abd A.El, Kichanov S.E., Taman M., Nazarov K.M. Penetration of water into cracked geopolymer mortars by means of neutron radiography. Constr. Build. Mater. 2020, Vol. 256, pp.119471.

3 Abd A.El, Kichanov S.E., Taman M., et al. Determination of moisture distributions in porous building bricks by neutron radiography. Applied Radiation and Isotopes. 2020, Vol. 156, No. 108970.

4 Angst U. M., Hooton R. D., Marchand J., et al. Present and future durability challenges for reinforced concrete structures. Mater Corros. 2012, Vol. 63, No.12, pp. 1047-1051. 
5 Müller H. S., Haist M., Vogel M. Assessment of the sustainability potential of concrete and concrete structures considering their environmental impact, performance and lifetime. Constr. Build. Mater. 2014, Vol. 67, pp. 321-337.

6 Wang K., Jansen D.C., Shah S.P., et al. Permeability study of cracked concrete. Cem. Conc. Res. 1997, Vol.27, pp. $381-393$.

7 Gummerson R.J., Hall C., Hoff W.D., et al. Unsaturated water flow within porous materials observed by NMR imaging, Nature. 1979, Vol. 281, pp. 56-57.

8 Baker P.H., Bailly D., Campbell M., et al. The application of x-ray absorption to building moisture transport studies. Measurement. 2007, Vol. 40(9-10), pp. 951-959.

9 Zhang P., Wittmann F.H., Zhao T. J., et al. Observation and quantification of water penetration into frost damaged concrete by neutron radiography. Restoration of Buildings and Monuments. 2010, Vol. 16, pp. $195-210$.

10 Zhang P., Wittmann F.H., Lura P., et al. Application of neutron imaging to investigate fundamental aspects of durability of cement based materials: A review. Cem. Conc. Res. 2018, Vol. 108, pp. 152-166.

11 Anderson S., McGreevy R.L., Bilheux H.Z. Neutron Imaging and Applications: A Reference for the Imaging Community. Springer US, New York, Edition 1, 2009, p. 341.

12 Lehmann E.H., Kaestner A., Gruenzweig C., et al. Materials research and non-destructive testing using neutron tomography methods. Int. J. Mater. Res. 2014, Vol. 105, pp. 664-670.

13 Perfect E., Cheng C.-L., Kang M., et al. Neutron imaging of hydrogen-rich fluids in geomaterials and engineered porous media: A review, Earth-Sci. Rev. 2014, Vol. 129, pp. 120-135.

14 Kichanov S.E., Kenessarin M., Balasoiu M., et al. Studies of the Processes of Hardening of Cement Materials for the Storage of Aluminum Radioactive Waste by Neutron Radiography. Phys. Part. Nuclei Lett. 2020, Vol. 17, No. 1, pp.73-78.

15 Kichanov S.E., Nazarov K.M., Kozlenko D.P., et al. Neutron tomography studies of cement-based materials used for radioactive waste conditioning, Rom. J. Phys. 2019, Vol. 64, No. 803.

16 BS EN196-3: Methods of Testing cement - part 3: Determination of Setting Times and Soundness. BSI Group, London, UK, 2005, 18p. 36p.

17 BS EN, 96-1: Methods of Testing cement: Determination of Strength. BSI Group, London, 2005,

18 ASTM C 230 /C 230M-14, Standard Specification for Flow Table for Use in Tests of Hydraulic Cement. ASTM International, West Conshohocken, PA, 2014, p. 6.

19 Kozlenko D.P., Kichanov S.E., Lukin E.V., et al. Neutron Radiography Facility at IBR-2 High Flux Pulsed Reactor: First Results. Physics Procedia. 2015, Vol. 69, pp. 87 - 91.

20 Kozlenko D. P., Kichanov S. E., Lukin E. V., et al. Neutron radiography and tomography facility at IBR-2 reactor. Phys. Part. Nuclei Lett. 2016, Vol. 13, pp. 346-351.

21 Schneider C. A., Rasband W. S., Eliceiri K.W. NIH Image to Image J: 25 years of image analysis. Nat. Methods. 2012, Vol. 9(7), pp. 671-675.

22 Hall C. Water movement in porous building materials-I. Unsaturated flow theory and its applications. Build. Environ. 1977, Vol. 12, pp. 117-125.

23 Brew D. R. M., De Beer F.C., Radeb M.J., et al. Water transport through cement-based barriers - A preliminary study using neutron radiography and tomography. Nucl. Instrum. Meth. A. 2009, Vol. 605, pp.163-166.

24 Singh S.B., Munjal P., Thammishetti N. Role of water / cement ratio on strength development of cement mortar. J. Build. Eng. 2015, Vol. 4, pp. 94-100.

25 Philip J.R. Theory of infiltration. Advances in Hydroscience. 1969, Vol. 5, pp. $215-296$.

26 Philip J.R. The theory of infiltrate Sorptivity and algebraic infiltration. Soil Sci. 1957, Vol. 84(3). pp.257-264.

27 Zhao Y., Xue S., Han S., et al. Effects of microstructure on water imbibition in sandstones using X-ray computed tomography and neutron radiography J. Geophys. Res. Solid Earth, 2017, Vol. 122, pp. 4963-4981.

28 Lucero C.L. Quantifying moisture transport in cementitious materials using neutron radiography. 2015, Purdue University, Open Access Theses, pp. 132. 